\title{
A New Controller for Voltage and Stability Improvement of Multi Machine Power System Tuned by Wind Turbine
}

\author{
Issam Griche ${ }^{1,2,3^{*}}$, Sabir Messalti ${ }^{1,3}$, Kamel Saoudi ${ }^{2}$, Mohamed Yaakoub Touafek $^{2}$, Fares Zitouni ${ }^{4}$ \\ ${ }^{1}$ Department of Electrical Engineering, Faculty of Technology, University of M'sila, M'sila 28000, Algeria \\ ${ }^{2}$ Department of Electrical Engineering, Faculty of Engineering, University of Bouira, Bouira 10000, Algeria \\ ${ }^{3}$ Mechatronics Laboratory (LMETR) - E1764200 Optics and Precision Mechanics Institute Ferhat Abbas University Setif 1, \\ Setif 19000, Algeria \\ ${ }^{4}$ Sonelgaz, Transmission Network Manager, Setif 19000, Algeria
}

Corresponding Author Email: issam.grich@univ-bouira.dz

https://doi.org/10.18280/mmep.080110

Received: 3 August 2020

Accepted: 14 November 2020

\section{Keywords:}

power system, voltage improvement, wind turbine (WT), ANFIS controller

\section{INTRODUCTION}

Over the last few years, electric power system a have been combined with new generation connected to the power systems. As the world shifts, its emphasis from fossil fuel to clean power, researchers are desperately searching for the perfect clean energy technology. Wind, solar, wave, tidal, biofuel and biomass are all experiencing renewed interest and new research funding. One alternative clean energy technology that bears looking at is wind powers which has been used for powering transportation and industrial equipment in cities and replace the power plants $[1,2]$. Wind power generation is growing rapidly in recent years around the world. The conventional point forecasting of wind power is difficult to meet the demand of power grid planning and operation $[3,4]$.

A dynamic and nonlinear power system in presence of wind generator one of the most complex man made system the world have seen [5]. Small instabilities usually transpires due to changes in inertia, load conditions variations, electrical fault, voltage failure and a major change in continuous demand supply [6]. Therefore, new controllers are able to improve the voltage and stability damping by the coordinated control based wind power generation was discussed by the authors [7-11]. From the studies, wind turbine equipped with ANFIS controller has been applicable to deal the problem of stability and voltage improvement issues with the power scheme. Among them, high penetration of wind power generation has been tested [12, 13]. The focus of recent research has been on a stability problem during integration in power system [14]. However, very few publications can be found are available in the literature that discusses to solve the problem of stability and voltage regulation [14].

In the past few years, the ANFIS controller has been widely used in the wind power generation using an optimization algorithm to select reasonable parameters of the model [15]. However, from the literatures, it shows that the optimal coordinated design of different controllers have been addressed to a single machine whereas the less attention have been paid for multi machine power system. In sum, it is clear from the literature survey that the application of different techniques to solve the problem of voltage enhancement has been established. This encourages us to propose a new technique to deal with this problem [16-18].

Recently, to satisfy the necessity of the control system and escape the rising difficulty encountered by the conventional regulators scheme, Artificial Intelligence controllers have been widely developed [19]. A Neural Network observer of doubly fed induction generator (DFIGs) was established to increase the oscillatory stability of the power system including wind turbine [20]. A coordination of ANFIS and type-2 fuzzy system was joined to increase a large-scale IEEE 39-bus multimachine test system [21]. Also, a new technique of a novel fuzzy neural PI controller based static synchronous series compensator and a fuzzy controller having a novel assembly was instantaneously established [22] for suppressing of low frequency oscillations on a 4-machine, IEEE test system. Another novel fuzzy rule matrix was design [23] for fuzzy logic system to efficiently damped low frequency oscillations of a SMIB and 4-machine, IEEE test system.

In this designed, an effective approach ANFIS controller to advance the test system voltage profile and reduce the oscillations of the power system in presence of the wind turbine connected in the bus load which strong three-phase fault is applied.

The main contributions of this work are given by the following points:

- Proposed a new ANFIS controller to improve the 
mechanical power required into the synchronous machines

- The effectiveness of the ANFIS controller to enhance the stability and voltage profile.

- The advantages of the proposed control approach have been validated considering the IEEE 9 Bus power system in fault disturbances.

The arrangement of this paper is presented: Section 2 describes the power system under study. Section 3 the overall framework of the proposed method which introduces the methodologies of the proposed controller. Section 4 illustrates the time domain simulation which provides the results of the proposed method and comparative studies. The conclusions are drawn in Section 5.

\section{POWER SYSTEM MODELING UNDER STUDY}

Figure 1 shows the IEEE 9bus power system including 3 generators linked together by 6 lines $230 \mathrm{kV}$ lines of different length which the parameters are given [24]. It was purposely designed to review low frequency electromechanical oscillations in large interconnected power systems. Regardless of its small size, it mimics very closely the behavior of typical systems in actual operation. Each synchronous generator is equipped with rated power 247.5, 192, 128 MVA respectively. The load is represented as constant impedances. Since the surge impedance loading of a single line is about $125,90,100$ MW located in the bus 5, 6 and 8 respectively. To study the efficient method of wind, a three wind farm are connected in 3 bus loads, bus 5, 6 and 8 which the details in ref. [25].

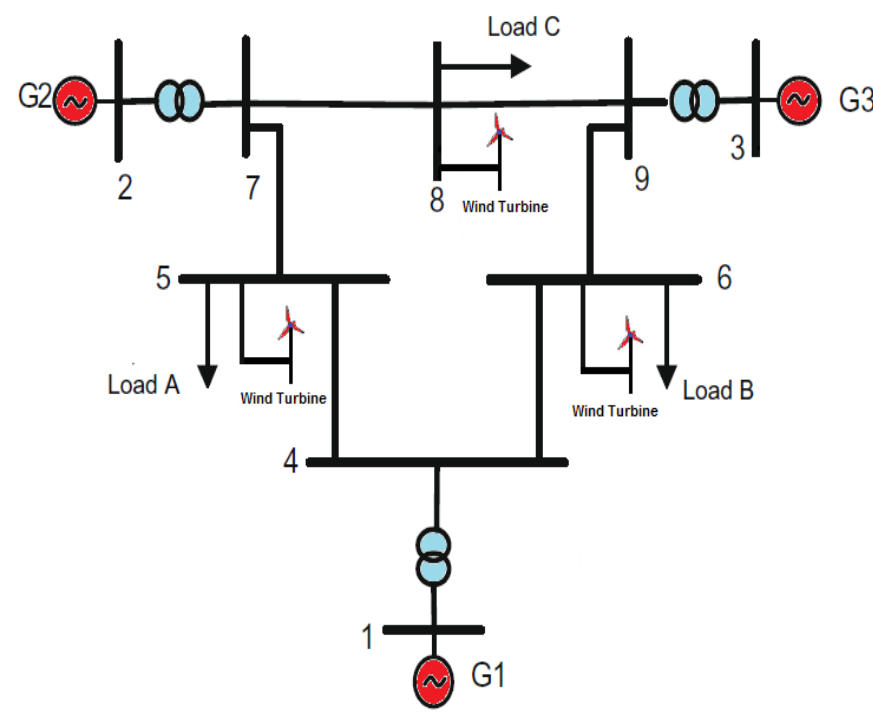

Figure 1. Structure of the 9-bus power system under study

The effectiveness of the proposed controller is evaluated under multiple system operating conditions as below:

- Condition-1: without integration of wind farm and without controller;

- Condition-2: with integration of wind farm and with conventional regulator;

- Condition-3: with integration of wind farm and with ANFIS controller.

\subsection{Synchronous generator model (SGM)}

In this study, the dynamic behavior of machines is given by:

$$
\begin{gathered}
\dot{\delta}_{i}=\left(\omega_{i}-\omega_{b}\right) \\
\dot{\omega}_{i}=\frac{\omega_{b}}{2 H_{i}}\left[P_{m i}-P_{e i}-D_{i}\left(\omega_{i}-\omega_{b}\right)\right] \\
\dot{E}_{q i}^{\prime}=\frac{1}{T^{\prime}{ }_{d 0 i}}\left[V_{e x i}-E_{q i}^{\prime}+\left(x_{d i}-x_{d i}^{\prime}\right) I_{d i}^{\prime}\right] \\
\dot{E}_{d i}^{\prime}=\frac{1}{T^{\prime}{ }_{q 0 i}}\left[-E_{q i}^{\prime}-\left(x_{q i}-x_{q i}^{\prime}\right) I_{q i}^{\prime}\right] \\
\frac{d V_{e x}}{d t}=\frac{1}{T_{E}}\left[V_{R}-\left(S_{E}+K_{E}\right) V_{e x}\right] \\
\frac{d V_{1}}{d t}=\frac{1}{T_{R}}\left(V_{r e f}-V_{t}-V_{1}\right) \\
\frac{d V_{2}}{d t}=\frac{1}{T_{F}}\left(K_{F} \frac{d V_{e x}}{d t}-V_{2}\right)
\end{gathered}
$$

\subsection{Wind turbine model}

The mechanical power $P_{W}$ captured from a wind turbine of a blade radius $(\mathrm{R})$ running in a wind stream of velocity $V_{w}$ is given by [25]:

$$
P_{W}=\frac{1}{2} \rho \pi R^{2} C_{p}(\lambda, \beta) V_{w}
$$

The tip speed ratio (TSR) is given by:

$$
\lambda=\frac{R \omega_{T}}{V_{w}}
$$

The power coefficient curve is approximated analytically by:

$$
C_{p}(\lambda, \beta)=0.5109\left(\frac{116}{X}-0.4 \beta-5\right) \exp \left(-\frac{21}{X}\right)+116 \lambda
$$

where: $X=\frac{1}{\lambda+0.08 \beta}-\frac{0.035}{1+\beta^{3}}$.

In addition the global wind power generated is given by the following equation:

$$
P_{\text {WTotal }}=\sum_{i=1}^{n} P_{W}
$$

In our case, the number of wind turbine is 21 which the total power injected is $35.28 \mathrm{MW}$. 


\section{DESIGN OF PROPOSED CONTROLLER}

\subsection{Conventional speed regulator}

A conventional speed regulator for synchronous machine system shown in Figure 2 is used in this research [24].

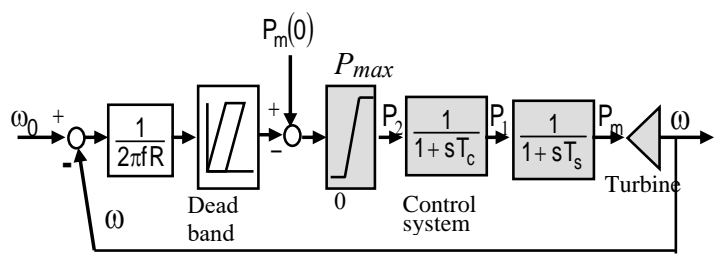

Figure 2. Block diagram of governor turbine model for synchronous generator

$$
\begin{gathered}
\frac{d P_{m}}{d t}=\frac{1}{T_{s}}\left(P_{1}-P_{m}\right) \\
\frac{d P_{1}}{d t}=\frac{1}{T_{c}}\left(P_{2}-P_{1}\right) \\
P_{2}=P_{m}(0)-\frac{1}{R}\left[\frac{\omega_{b}-\omega}{2 \pi f} \pm D B t\right]
\end{gathered}
$$

\subsection{Adaptive Neuro-Fuzzy Inference System (ANFIS)} controller

\subsubsection{ANFIS controller overview}

Adaptive Neuro-Fuzzy Inference System (ANFIS) controller structure, is obtained by combining the generalization, learning and adaptation features of ANN and FLC, provides successful results in many areas. The most important advantage of this controller structure is its ease of model-free design. These features of the proposed controller are among the reasons why it is preferred more than other controllers. Moreover, these features facilitate the control of systems that contain a lot of uncertainty in their structure.

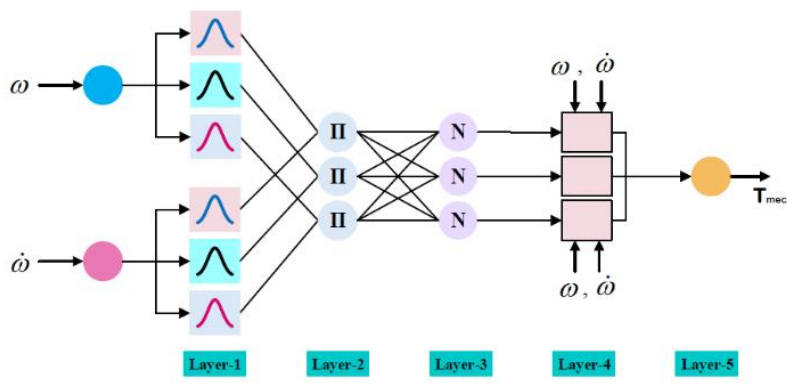

Figure 3. Two-Input Sugeno Type ANFIS Structure

This research ANFIS structure is a neural network (NN) which is trained at the beginning to established IF-THEN fuzzy rules and define membership functions for input and output test system parameters. This structure is basically a multi-layer $\mathrm{NN}$ and it learns using the back-propagation algorithm. To demonstrate how the ANFIS system works, when a training input-output example is presented to the system, the back-propagation algorithm calculates the output of the system and compares it with the preferred output of the training example. The error is transmitted backwards over the network from the output layer to the input layer. The neuron activation functions are adjusted as the error is transmitted. The diagram assembly of the proposed controller that is engaged in the control algorithm is presented in Figure 3.

\subsubsection{ANFIS controller design}

The output of neural $i$ in layer 1 is can be given by:

$$
U_{i}^{l}=\sum_{j}^{N_{l-1}} w_{i j}^{l} \times O_{i}^{l-1}+b_{i}^{l}
$$

$$
O_{i}^{l}=g^{l}\left(U_{i}^{l}\right)
$$

$l=1,2$ : number of layer.

$g^{l}$ activation function of neural of layer $l$.

We can rewrite the above equations in matrix form as follows:

$$
\begin{gathered}
\underline{U}^{l}=W^{l} \times \underline{O}^{l-1}+\underline{b}^{l} \\
\underline{O}^{l}=\underline{g}^{l}\left(\underline{U}^{l}\right)
\end{gathered}
$$

where: $\underline{U}^{l}=\left(U_{1}^{l}, U_{2}^{l}, \ldots . ., U_{N}^{l}\right)^{T}$, $\underline{O}^{l}=\left(O_{1}^{l}, O_{2}^{l}, \ldots \ldots, O_{N}^{l}\right)^{T}, \underline{b}^{l}=\left(b_{1}^{l}, b_{2}^{l}, \ldots \ldots, b_{N}^{l}\right)^{T}$ and $W^{l}=\left(\begin{array}{cccc}w_{11}^{l} & w_{12}^{l} & \cdots & w_{1 N_{l-1}}^{l} \\ w_{21}^{l} & w_{22}^{l} & \cdots & w_{2 N_{l-1}}^{l} \\ \vdots & \vdots & \ddots & \vdots \\ w_{N_{l} 1}^{l} & w_{N_{l} 2}^{l} & \cdots & w_{N_{l} N_{l-1}}^{l}\end{array}\right)$

\subsubsection{Proposed ANFIS controller implementation}

The identification of linear systems is currently a field well mastered by the automation engineer. However, many real processes are complex and have non-linear dynamics. The Figure 4 shows the general diagram of neural identification. In this figure, the neural network is used in parallel with a black box type process to be identified. The error equation $e_{i}=y-y$ is used by an appropriate learning algorithm.

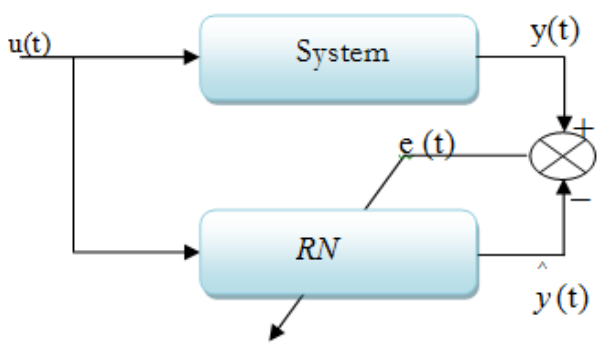

Figure 4. Proposed ANFIS controller

The proposed controller structure is modeled in Matlab / Simulink environment to be used in simulation studies as shown in Figure 5. 


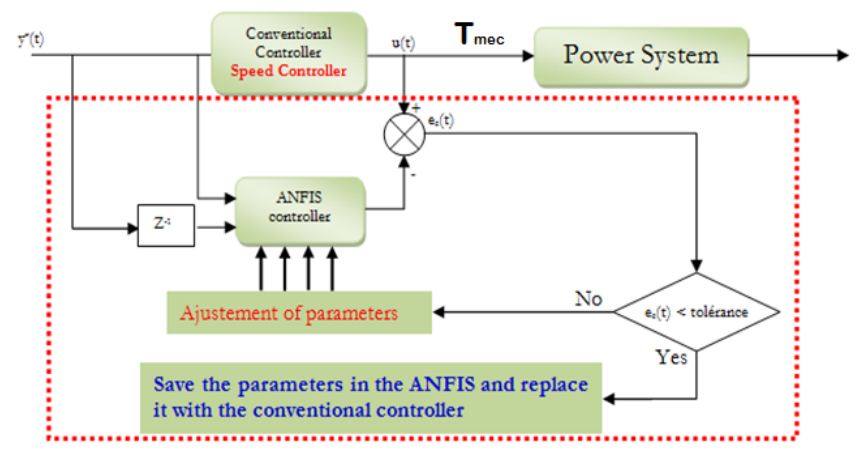

Figure 5. Simulation procedure of the proposed controller

In these conditions, the electrical torque is optimized at the optimum operating speeds of synchronous generator shown in Figure 6.

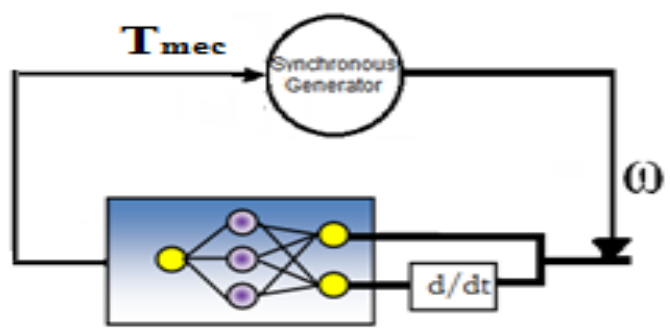

ANFIS Controller

Figure 6. ANFIS controller implementation

The inputs are specified for the proposed controller structure. The inputs of ANFIS controller are determined as being the speed of synchronous generator and its derivative. The Gaussian Membership Functions (MFs) are chosen for each input in layer-i which is called as fuzzification layer [26]. The following mathematical expression can be written for Gaussian MF.

$$
o_{j}^{i}=\exp \left|\frac{\left(x_{i}-m_{i j}\right)^{2}}{2\left(\sigma_{i j}\right)^{2}}\right|
$$

where, $\sigma$ and $m$ present the standard deviation and mean of MF. In order to update the antecedent and the consequent part parameters through backpropagation algorithm, the squared error (E) which reduces tracking error (e) is expressed as [27]:

$$
E=\frac{1}{2} e^{2}
$$

If parameter of the proposed controller structure to be adapted is determined as $\vartheta$, the following equation can be used to update the parameter.

$$
\vartheta(k)=\vartheta(k-1)+\left(-\eta \frac{\partial E(k)}{\partial \vartheta(k)}\right)
$$

Here, $\eta$ is the learning rate. The chain rule is employed to get the partial derivative. The derivative chain up to the output of the ANFIS is determine as:

$$
\delta^{1}=\frac{\partial E}{\partial \omega_{1}} \frac{\partial \omega_{1}}{\partial T_{m e c}} \frac{\partial T_{m e c}}{\partial y^{6}}
$$

This controller allows automatic generation of fuzzy rules with five sets based on the SUGENO inference model shown in Figure 7.

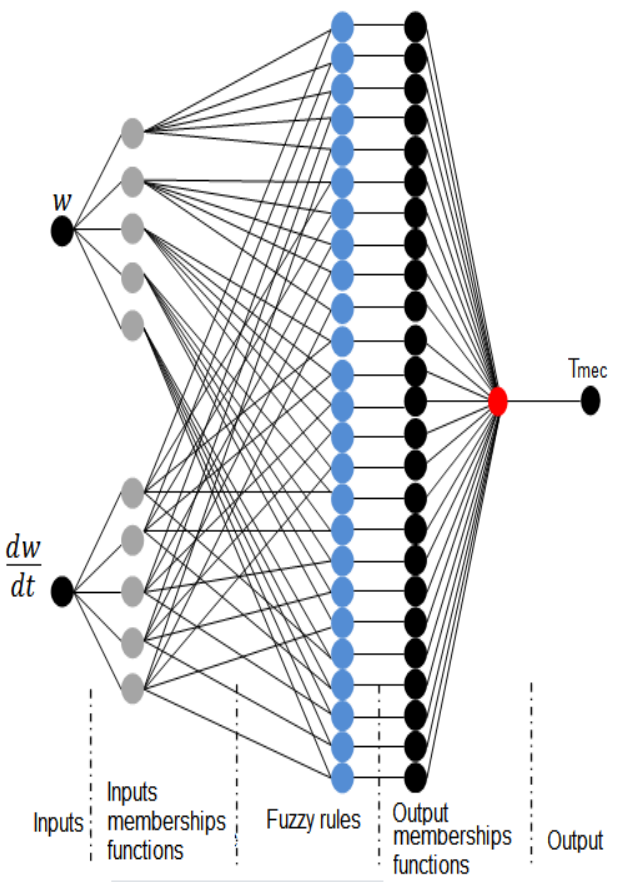

Figure 7. Proposed ANFIS controller
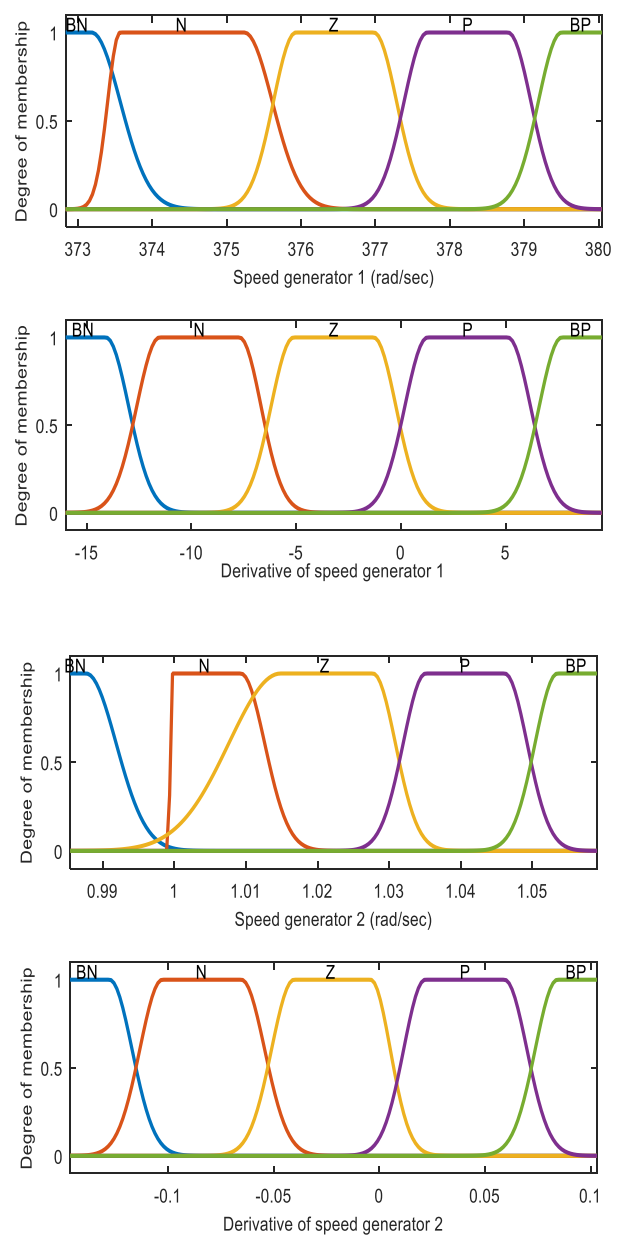

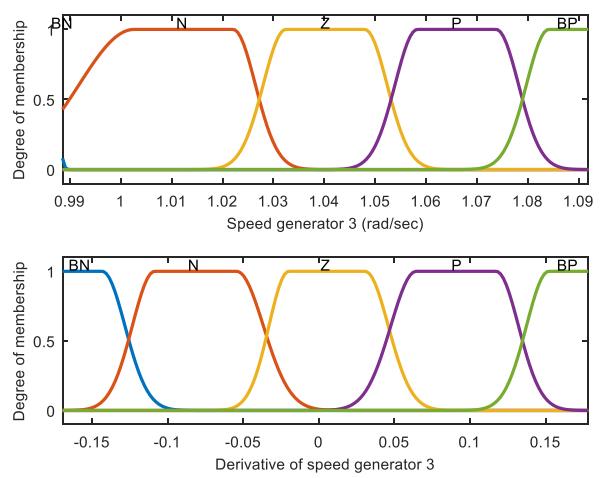

Figure 8. Three membership function obtained by ANFIS of 3 machines

In our case, the decentralized controller of three machines which the membership function obtained by ANFIS is given by Figure 8 .

\section{TIME-DOMAIN SIMULATION ANALYSIS}

In order to demonstrate the efficiency, a 3 machines- 9 bus system is used to evaluate the proposed model. Time domain simulations using Matlab-Simulink environment are performed for a strong three-phase fault of $0.1 \mathrm{sec}$ applied to bus 4 at line 4-5 shown in Figure 9.

Three distinct scenarios for Test system is considered to demonstrate the ability of the controller to enhance the stability and voltage of the power test system.

The discussions of all the simulation works undertaken in this investigation is described in this section.

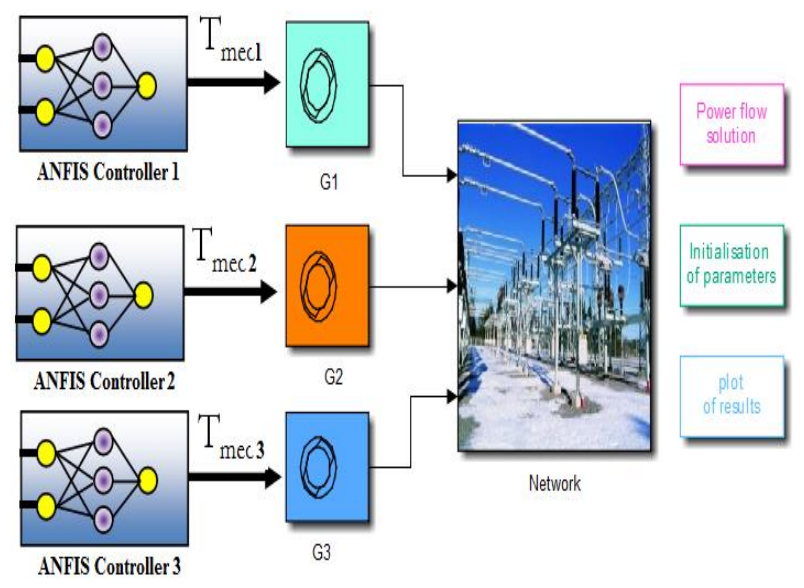

Figure 9. Bloc of simulation in Matlab

Scenario 1: A three-phase fault in a transmission line between bus 4 and bus 5 at $\mathrm{t}=2 \mathrm{~s}$ and cleared at $\mathrm{t}=2.1 \mathrm{~s}$. This scenario without integration of wind farm and without controller.

Scenario 2: A three-phase fault in a transmission line between bus 4 and bus 5 at $\mathrm{t}=2 \mathrm{~s}$ and cleared at $\mathrm{t}=2.1 \mathrm{~s}$. This scenario with integration of wind farm and with conventional regulator

Scenario 3: A three-phase fault in a transmission line between bus 4 and bus 5 at $\mathrm{t}=2 \mathrm{~s}$ and cleared at $\mathrm{t}=2.1 \mathrm{~s}$. This scenario with integration of wind farm and with ANFIS controller.

\subsection{Scenario 1}

In this scenario, test system is taken as an operating point, because compared with other cases, its having most stable mode. Figure 10 display the open loop eigen values and its damping ratio without integration of wind turbine and without controllers.

It can be noted that the system is transiently stable in these conditions.

\subsection{Scenario 2}

For this simulation, it is assumed that 3 wind farms are connected in the bus 5,6 and 8. This wind farm content 21 wind turbine each $1.68 \mathrm{MW}$ [20]. In this simulation, the 3 machines are equipped by the conventional regulator. Figure 11 displays the oscillations for the test system after fault. It is obvious from this situation that the system loses its stability. As predicted, the criteria of stability in the presence of wind turbine have a longer value.
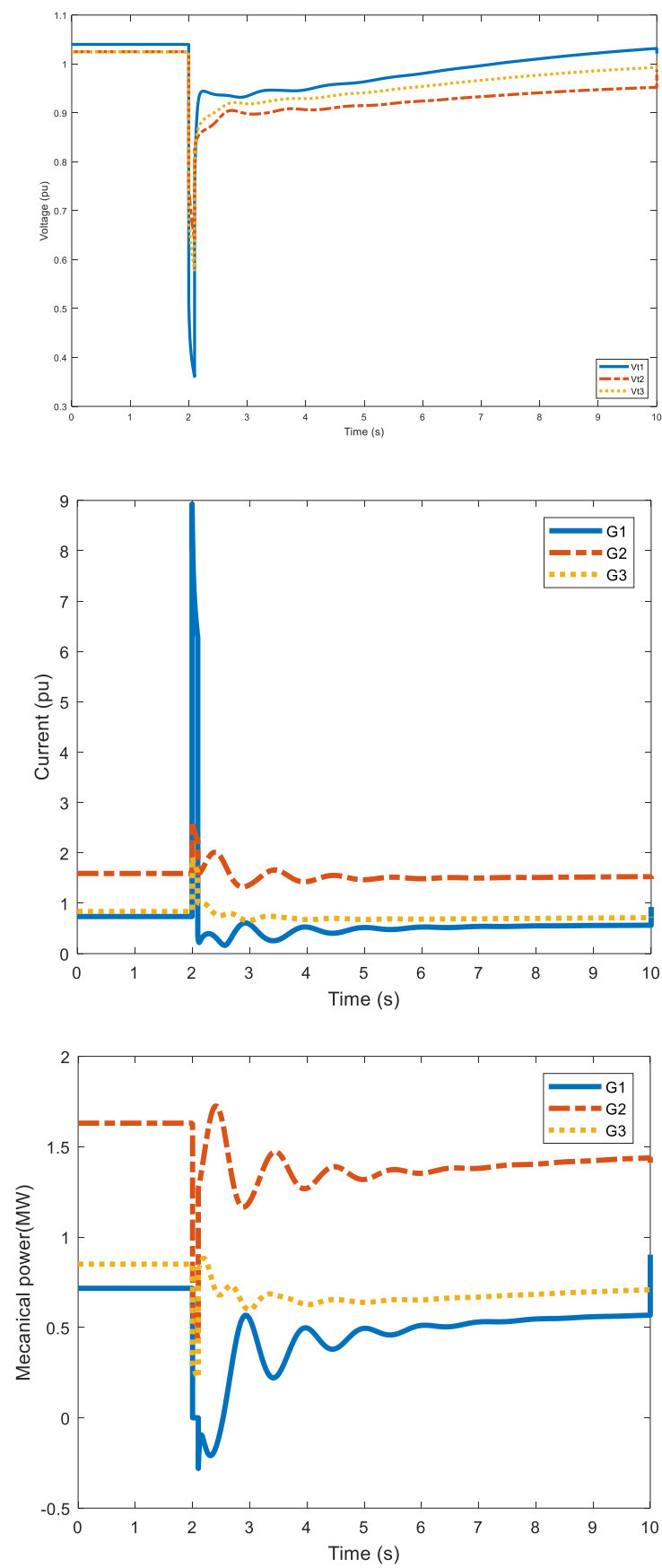


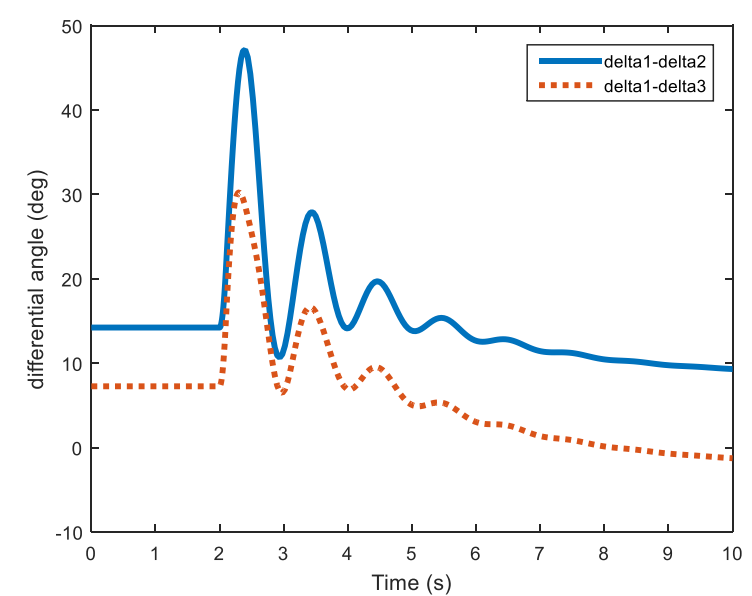

Figure 10. Simulation results without wind farm integration and without controller
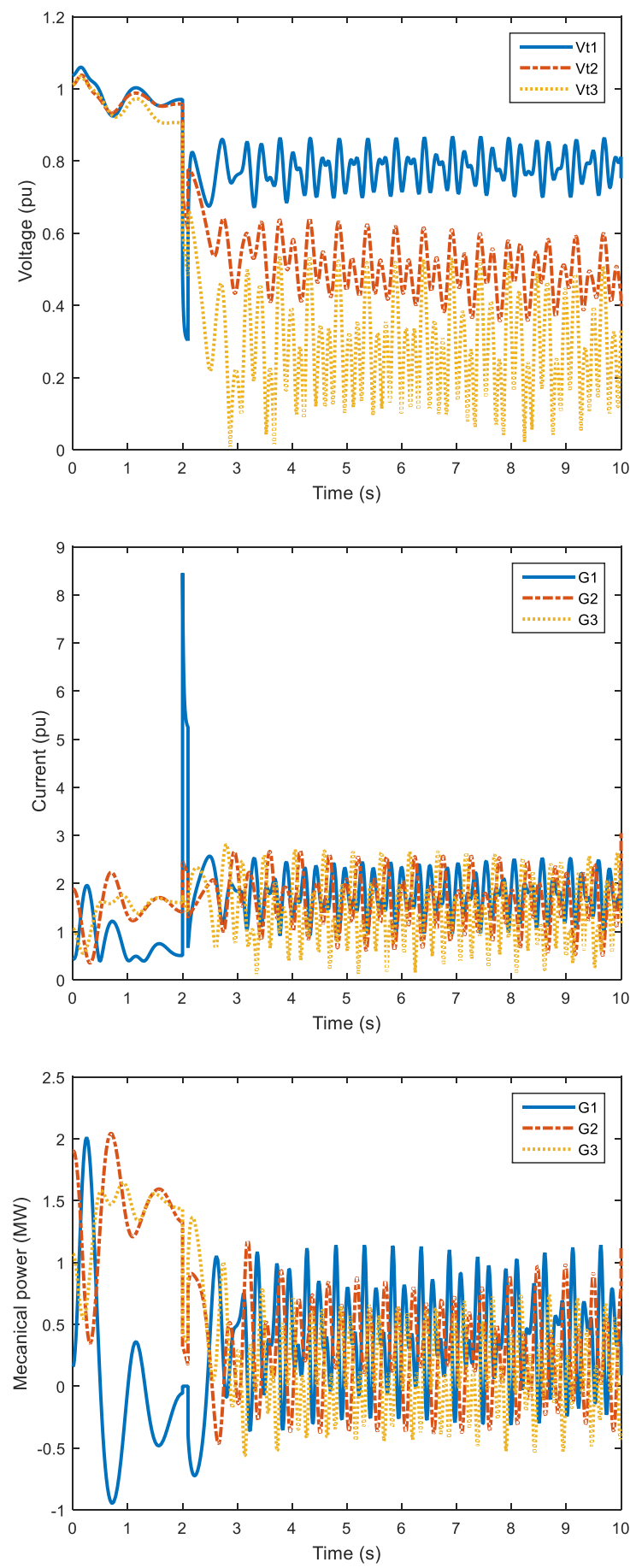

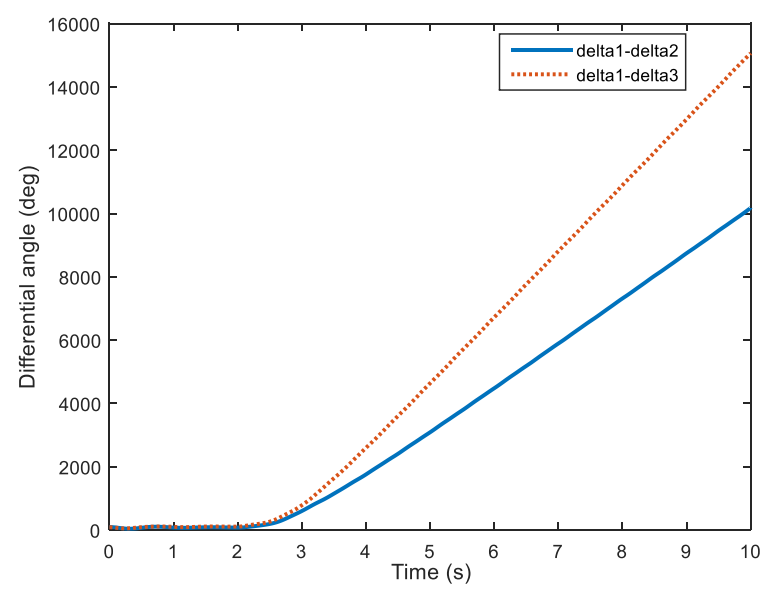

Figure 11. Simulation results with wind farm integration and with conventional regulator

\subsection{Scenario 3}

Also, to examine the reliability of the proposed controller, the proposed ANFIS is applied to large power system and its performances were compared to scenario 1 and 2 .

Each Figure 12 includes three plots same as in the test system. The system response with the new controller response reveals that, the dynamic stability of the test system is greatly enhanced using the proposed controller in presence of wind turbine. The proposed controllers fail to give performances containing the minimal number of oscillations. It is noteworthy that, the proposed controller is suitable for large power systems also.
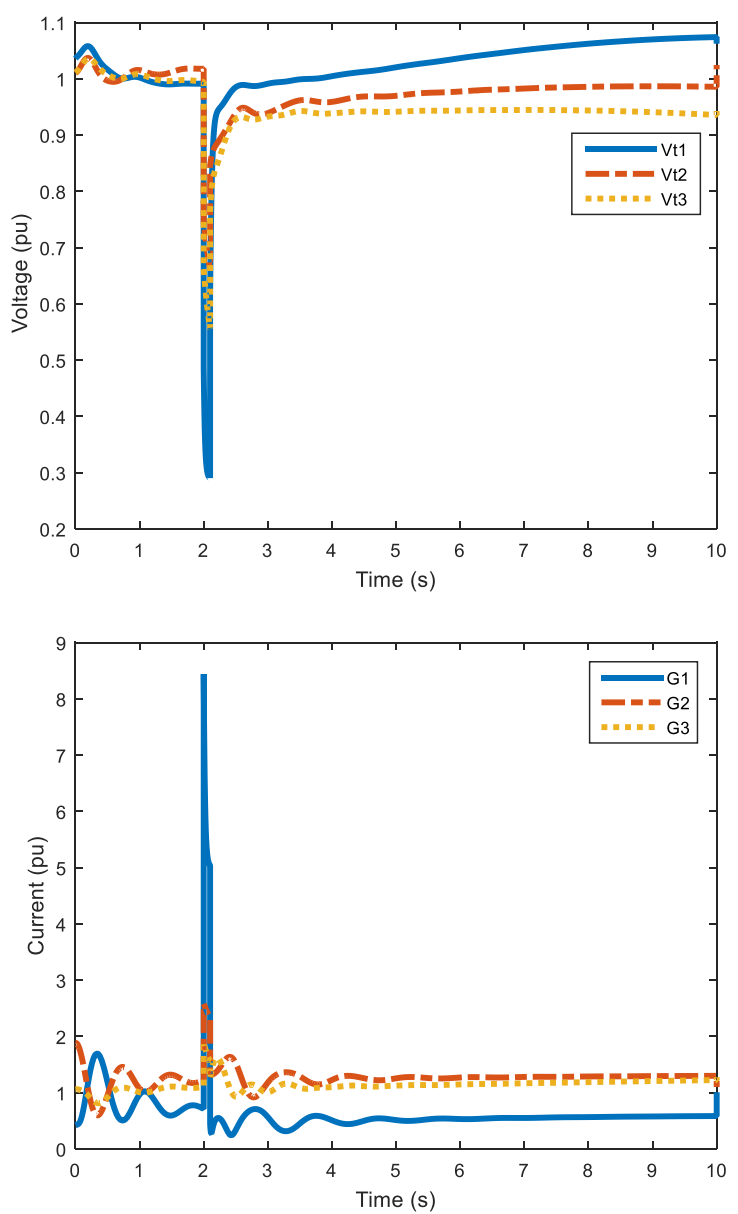

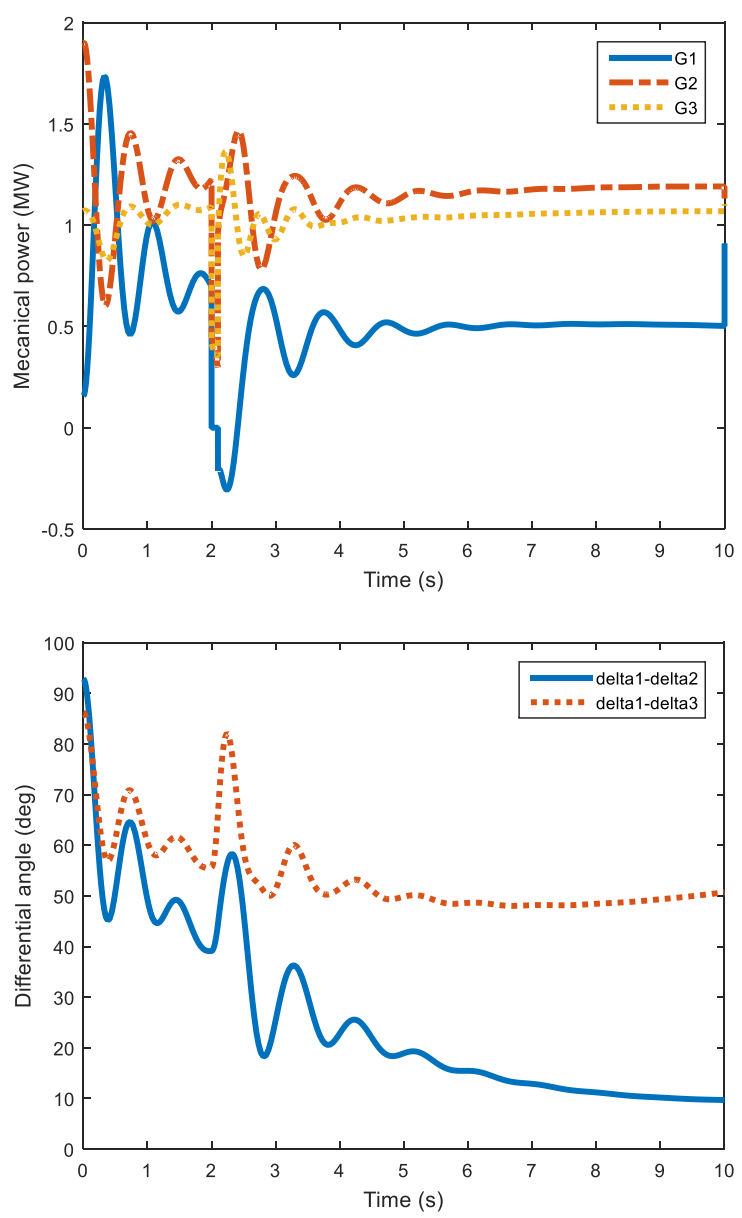

Figure 12. Simulation results with wind farm integration and with ANFIS controller

\section{CONCLUSION}

In this paper, ANFIS controller has been used to improve the performance of power system in presence of wind turbine. A fair study was conducted on three scenarios: the first without integration of wind farm and without the proposed controller, the second with integration of wind farm and with the conventional regulator and finally with integration of wind farm and with ANFIS controller. The results have been showed that the ANFIS controller capable of improving the dynamical response of power system. The proposed controller was successfully applied to the coordinated design of power system parameters with wind energy generation in order to enhance the voltage of the multi machine power system. The simulations have confirmed the robustness and superiority of the proposed controller for damping characteristics to system oscillations above various types of transient disturbances. These results demonstrate that the proposed controller confirms better disturbance rejection, voltage control, keeps the control quality in the wider operating range and damps the power system oscillations.

\section{ACKNOWLEDGEMENTS}

The authors would like to thank Editors and reviewers for their pertinent comments and suggestions to improve our paper. The authors thank the General Directorate of Scientific
Research and Technological Development (DGRSDT).

\section{REFERENCES}

[1] Bo, Z.Q., Aggarwa, R.K., Johns, A.T., Zhang, B.H., Ge, Y.Z. (1997). New concept in transmission line reclosure using high frequency fault transients. IEE Proceedings Generation, Transmission and Diwfli, 144(4): 1359-7051. https://doi.org/10.1049/ip-gtd:19971102

[2] Anderson, P.M., Fouad, A.A. (2003). Power System Control and Stability Piscataway. N.J.: WileyInterscience.

[3] Speidel, S., Braunl, T. (2016). Leaving the grid-The effect of combining home energy storage with renewable energy generation. Renew Sustainable Energy Rev., 60: 1213-1224. https://doi.org/10.1016/j.rser.2015.12.325

[4] Hammons, T.J. (2008) Integrating renewable energy sources into European grids. Int. J. Electr. Power Energy Syst., 30: 462-475. https://doi.org/10.1016/j.ijepes.2008.04.010

[5] Ni, K., Gan, C., Hu, Y., Member, S., Qu, R. (2020). Input-output small-signal stability analysis of A PLLfree direct power controlled partially power decoupled moreelectric shipboard propulsion system. IEEE Trans. Transp. $\quad$ Electrif., $\quad$ 7782: 1-15. https://doi.org/10.1109/TTE.2020.3044884

[6] Li, Y., Shuai, Z., Fang, J., Wu, X., John Shen, Z. (2020). Small-signal stability analysis method for hybrid AC-DC systems with multiple DC buses. IEEE J. Emerg. Sel. Top. Circuits Syst., 3357(c): 1-11. https://doi.org/10.1109/JETCAS.2020.3044091

[7] Li, H.Z., Guo, S., Li, C.J., Sun, J.Q. (2013). A hybrid annual power load forecasting model based on generalized regression neural network with fruit fly optimization algorithm. Knowledge-Based Systems, 37: 378-387. https://doi.org/10.1016/j.knosys.2012.08.015

[8] Ganjefar, S., Alizadeh, M. (2012). Inter-area oscillations damping by multi-objective wavelet neural inverse controlled SSSC. International Review of Electrical Engineering, 7(2): 281-290.

[9] Saidi, S., Abbassi, R., Chebbi, S. (2015). Fuzzy logic controller for three level shunt active filter compensating harmonics and reactive power. International Journal of Adaptive Control and Signal Processing, 45: 320-329. https://doi.org/10.1016/j.epsr.2009.04.003

[10] Alizadeh, M., Tofighi, M. (2013). Full-adaptive THENpart equipped fuzzy wavelet neural controller design of FACTS devices to suppress inter-area oscillations. Neuro Computing, 118: 157-170. https://doi.org/10.1016/j.neucom.2013.03.001

[11] Ghadimi, N. (2015). A new hybrid algorithm based on optimal fuzzy controller in multi-machine power system. Complexity, 21(1): 78-93. https://doi.org/10.1002/cplx.21544

[12] Tvakoli, A.R., Seifi, A.R., Arefi, M.M. (2016). FuzzyPSS and fuzzy neural network non-linear PI controller based SSSC for damping inter-area oscillations. Trans. Inst. Meas. Control, 40(3): 733-745. https://doi.org/10.1177\%2F0142331216665688

[13] Domínguez-García, J.L., Gomis-Bellmunt, O., Bianchi, F.D., Sumper, A. (2012). Power oscillation damping supported by wind power: A review. Renewable and Sustainable Energy Reviews, 16(7): 4994-5006. 
https://doi.org/10.1016/j.rser.2012.03.063

[14] Mahmud, N., Zahedi, A. (2016). Review of control strategies for voltage regulation of the smart distribution network with high penetration of renewable distributed generation. Renew Sustainable Energy Rev., 64: 582-595. https://doi.org/10.1016/j.rser.2016.06.030

[15] Wu, Y.K., Han, G.Y., Lee, C.Y. (2013). Planning ten onshore wind farms with corresponding interconnection network and power system analysis for low-carbonisland development on Penghu Island, Taiwan. Renewable Sustainable Energy Rev., 19: 531-540. https://doi.org/10.1016/j.rser.2012.10.043

[16] Slotine, J.J.E., Li, W.P. (1991). Applied Nonlinear Control. Prentice-Hall, Englewood Cliffs, NJ.

[17] Griche, I., Messalti, S., Saoudi, K., Touafek, M. (2019). A new adaptive neuro-fuzzy inference system (ANFIS) and PI controller to voltage regulation of power system equipped by wind turbine. European Journal of Electrical

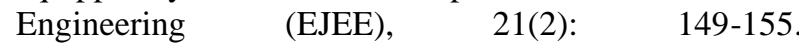
https://doi.org/10.18280/ejee.210204

[18] Griche, I., Messalti, S., Saoudi, K. (2019). Parallel fuzzy logic and pi controller for transient stability and voltage regulation of power system including wind turbine. Przegląd Elektrotechniczny. https://doi:10.15199/48.2019.09.10

[19] Çöteli, R., Açikgöz, H., Dandil, B., Tuncer, S. (2018). Real-time implementation of three-level inverter-based D-STATCOM using neuro27 fuzzy controller. Turkish J. Electr. Eng. Comput. Sci., 26: 2088-2103. https://doi.org/10.3906/elk-1708-281

[20] Li, X., Niu, Y., Fu, J., Zhang, X., Lin, Z., Niu, Y.G. (2018). A neural power system stabilizer of DFIGs for power system stability support. Int. Trans. Electr. Energy Syst., 28(6): 1-20. https://doi.org/10.1002/etep.2547

[21] Muljono, A.B., Ginarsa, I.M., Nrartha, I.M.A., Dharma, (2018). Coordination of adaptive neuro fuzzy inference system (ANFIS) and Type-2 fuzzy logic system-power system stabilizer (T2FLS-PSS) to improve a large-scale power system stability. Int. J. Electr. Comput. Eng., 8(1): 76-86. http://doi.org/10.11591/ijece.v8i1.pp76-86

[22] Wang, C., Gao, Q., Hou, Y.L., Min, H. (2016). Adaptive complementary fuzzy self-recurrent wavelet neural network controller for the electric load simulator system. Trans. Inst. Meas. Control, 8(3): 733-745. https://doi.org/10.11772F1687814016639250

[23] Sambariya, D.K., Prasad, R. (2017). A novel fuzzy rule matrix design for fuzzy logic-based power system stabilizer. Electr. Power Components Syst., 45(1): 34-48. https://doi.org/10.1080/15325008.2016.1234008

[24] Kundur, P. (1994). Power System Stability and Control. New York: McGraw Hill.

[25] Namjoo, N., Abbasi, F., Hassanzadeh, F., Asrari, H. Hajizadeh, A. (2014). A new hybrid control method for controlling back-to-back converter in permanent magnet synchronous generator wind turbines. J. Renewable
Sustainable $\quad$ Energy,
https://doi.org/10.1063/1.4884198

$133-142$.

] Kececioglu, O.F., Acikgoz, H., Yildiz, C., Gani, A. (2017). Power quality improvement using hybrid passive filter configuration for wind energy systems. J Electr Eng Technol, $12(1)$ : 207-216. https://doi.org/10.5370/JEET.2017.12.1.207

[27] Acikgoz, H., Kececioglu, O.F., Gani, A., Yildiz, C., Sekkeli, M. (2016). Improved control configuration of PWM rectifiers based on neuro - fuzzy controller. $\begin{array}{lll}\text { Springer } & \text { Plus, } & \text { 5(1142): }\end{array}$ https://doi.org/10.1186/s40064-016-2781-5

\section{NOMENCLATURE}

\begin{tabular}{|c|c|}
\hline$H_{i}$ & Inertia constant of the $\mathrm{i}$-th generator \\
\hline$D_{i}$ & Damping constant of the $\mathrm{i}$-th generator \\
\hline$\omega_{i}$ & Rotor angular velocity of the i-th generator \\
\hline$\delta_{i}$ & Rotor angle of the $\mathrm{i}$-th generator \\
\hline$P_{m i}$ & Mechanical input power of the i-th generator \\
\hline$P_{e i}$ & Electrical input power of the i-th generator \\
\hline$\omega_{b}$ & Rotating angular velocity \\
\hline$T_{d 0 i}^{\prime}, T_{q 0 i}^{\prime}$ & $\begin{array}{l}\mathrm{d} \text {-axis and q-axis transient time constants of } \\
\text { the i-th generator }\end{array}$ \\
\hline$E_{d i}^{\prime}, E_{q i}^{\prime}$ & $\begin{array}{l}\text { d-axis and q-axis transient emf of the i-th } \\
\text { generator }\end{array}$ \\
\hline$x_{d i}^{\prime}, x_{q i}^{\prime}$ & $\begin{array}{l}\text { d-axis and q-axis transient reactances of the } \\
\text { i-th generator }\end{array}$ \\
\hline$I_{d 0 i}^{\prime}, I_{q 0 i}^{\prime}$ & $\begin{array}{l}\text { d-axis and q-axis of the generator currents of } \\
\text { the i-th generator }\end{array}$ \\
\hline$V_{e x}$ & Field voltage controlled \\
\hline $\mathrm{Vt}$ & Terminal generator voltage \\
\hline$K_{A}, K_{E}, K_{F}$ & Gains \\
\hline$T_{A}, T_{E}, T_{F}$ & Time constants \\
\hline$R$ & $\begin{array}{l}\text { Speed regulation of the conventional speed } \\
\text { regulator }\end{array}$ \\
\hline$T_{c}, T_{s}$ & Time constants \\
\hline$P_{m}(0)$ & Initial mechanical power \\
\hline$P_{1}, P_{2}$ & Intermediate state variables \\
\hline$D B t$ & Dead band travel. \\
\hline $\mathrm{R}$ & Blade radius of the wind turbine \\
\hline$V_{w}$ & Wind stream of velocity \\
\hline$\rho$ & Air density \\
\hline$C_{p}$ & Power coefficient of the wind turbine \\
\hline $\mathrm{n}$ & Number of wind turbine \\
\hline
\end{tabular}

